\title{
Histopathological responses to a short term intraductal cytotoxic agent treatment: results of a feasibility study J Rao*1, H Yang ${ }^{2}$, B Zhang ${ }^{2}$, W Zhang ${ }^{2}$ and S Love ${ }^{3}$
}

\author{
Address: ${ }^{1}$ UCLA David Geffen School of Medicine, Los Angeles, CA, USA, ${ }^{2}$ Cancer Hospital/Institute, Chinese Academy of Medical Sciences, \\ Beijing, PR China and ${ }^{3}$ Dr. Susan Love Research Foundation, Santa Monica, CA, USA \\ Email: J Rao* - jrao@mednet.ucla.edu \\ * Corresponding author
}

from 6th International Symposium on the Intraductal Approach to Breast Cancer Santa Monica, CA, USA. I9-2I February 2009

Published: 24 July 2009

BMC Proceedings 2009, 3(Suppl 5):S30 doi:I0.II86/1753-656I-3-S5-S30

This abstract is available from: http://www.biomedcentral.com/1753-656I/3/S5/S30

(c) 2009 Rao et al; licensee BioMed Central Ltd.

\section{Background}

Previous animal model studies from Sukumar and others demonstrated the effect of intraductal administration of cytotoxic agents in preventing the occurrence of breast cancer. To determine the feasibility of the approach in humans, a preliminary study was performed in patients who were diagnosed with breast cancer and were waiting for mastectomy. Two drugs, carboplatin and Pegylated Liposomal Doxorubicin (PLD) were tested. These drugs were selected based on the results of preclinical studies. This report presents findings of histopathological examination of breast tissue taken from patients received intraductal administration of these two agents.

\section{Methods}

This was an uncontrolled observational dose escalation study. A total of 31 subjects undergoing mastectomy for breast carcinoma were included in this study. There were 15 subjects in the Carboplatin arm, and these 15 were divided into 3 dosage groups (60,120, and $300 \mathrm{mg}$ ), with 5 subjects per dosage group. There were 16 subjects in the PLD arm (one patient was withdrawn because of a central lesion which precluded duct cannulation) and they were also divided into 3 dosage groups $(10,20,50 \mathrm{mg})$. The 30 subject's age ranged from 25.9 years to 75.6 years. After intraductal injection of drugs into patients for at least 24 hours (up to 5 days), mastectomy was performed and specimens were processed in the pathology laboratory. Specific attention was paid to compare the cannulated ducts (dye stained ducts) with non-cannulated ducts (no- dye stained ducts) for inflammatory response and ductal epithelial changes (eosinophilic cytoplasm, nucleoli, loss of epithelium), each scored as none, mild, moderate, to severe using routine HE sections. The examination was performed without specific knowledge of dose levels for each drug by two pathologists (JYR and HYY).

\section{Results/conclusion}

For Carboplatin group, there was a dose-response increase of inflammatory response at the levels of mild to moderate degree. There was also a dose-response increase in the ductal epithelial cell changes ( $\mathrm{P}<0.05$ for both). For PLD group, no severe inflammatory changes were seen in any dose group, and a non-significant trend $(P>0.05)$ of increased for mild to moderate inflammatory response was seen in nipple, in dye stained ducts, and stromal tissue. There was a significant increase $(\mathrm{P}<0.05)$ of epithelial response to the PLD treatment in ducts with dye versus ducts without dye in any given dose. However, the low dose level appeared to have more "mild" to "moderate" degree of change whereas the high dose group showed more "severe" epithelial cell change. No changes were seen in ducts without dye in the high dose group.

Together, short term intraductal treatment of cytotoxic agents may induce some degree of epithelial changes and some inflammatory response. However, the long term effect remains to be determined. 


\section{Acknowledgements}

This study was sponsored by Windy Hill Medical, Inc

Publish with Biomed Central and every scientist can read your work free of charge

"BioMed Central will be the most significant development for disseminating the results of biomedical research in our lifetime. " Sir Paul Nurse, Cancer Research UK

Your research papers will be:

- available free of charge to the entire biomedical community

- peer reviewed and published immediately upon acceptance

- cited in PubMed and archived on PubMed Central

- yours - you keep the copyright 